\title{
Laser induced forward transfer of graphene and other 2D materials and computational modelling of transfer enabling conditions (Conference Presentation) (Withdrawal Notice)
}

Adamantia Logotheti, Symeon Papazoglou, Dimitrios Kaltsas, Filimon Zacharatos, Leonidas Tsetseris, et al.

Adamantia Logotheti, Symeon Papazoglou, Dimitrios Kaltsas, Filimon Zacharatos, Leonidas Tsetseris, loanna Zergioti, "Laser induced forward transfer of graphene and other 2D materials and computational modelling of transfer enabling conditions (Conference Presentation) (Withdrawal Notice)," Proc. SPIE 11675, Synthesis and Photonics of Nanoscale Materials XVIII, 116750A (20 May 2021); doi: 10.1117/12.2577672

SPIE. Event: SPIE LASE, 2021, Online Only 


\section{Laser induced forward transfer of graphene and other 2D materials and computational modelling of transfer enabling conditions (Conference Presentation) (Withdrawal Notice)}

Adamantia Logotheti, ${ }^{1}$ Symeon Papazoglou, ${ }^{1}$ Dimitris Kaltsas, ${ }^{1}$ Filimon Zacharatos, ${ }^{1}$ Leonidas Tsetseris, ${ }^{1}$ Ioanna Zergioti ${ }^{1}$

${ }^{1}$ National Technical Univ. of Athens (Greece)

Proceedings Volume 11675, Synthesis and Photonics of Nanoscale Materials XVIII; $116750 \mathrm{~A}$

(2021) https://doi.org/10.1117/12.2577672

Event: SPIE LASE, 2021, Online Only

Online Publication Date: 5 March 2021

Withdrawn from Publication: 20 May 2021

Publisher's Note: This conference presentation, originally published on 5 March 2021, was withdrawn per author request. 